\title{
Endoparasitos em cobaias (Cavia porcellus) (Mammalia, Rodentia, Caviidae) provenientes de biotérios de criação e experimentação do município do Rio de Janeiro, Brasil
}

\author{
Endoparasites in guinea pigs (Cavia porcellus) (Mammalia, Rodentia, Caviidae) from breeding and \\ experimentation animal housing of the municipality of Rio de Janeiro, Brazil
}

\author{
Luciana Casartelli Alves ${ }^{\mathrm{I}}$ Cleide Cristina Apolinário Borges ${ }^{\mathrm{I}}$ Sidnei da Silva ${ }^{\mathrm{II}}$ \\ Sebastião Enes Reis Couto ${ }^{\mathrm{I}}$ Rodrigo Caldas Menezes ${ }^{\text {III }}$
}

\section{RESUMO}

Foi realizado um levantamento sobre a prevalência e intensidade de infecção de endoparasitos em cobaias convencionais de linhagem Short Hair provenientes de biotérios de criação (A) e experimentação (B) do município do Rio de Janeiro, Brasil, avaliando-se a eficácia das medidas de prevenção entre eles. Para a realização do estudo, utilizouse exame direto de mucosa e do conteúdo intestinal, a técnica de tricromo de Wheatley e exames coproparasitológicos pelas técnicas de Ritchie e Kinyoun. Os parasitos encontrados através da técnica de exame direto da mucosa e do conteúdo intestinal e de tricromo de Wheatley com as respectivas prevalências foram: Balantidium sp. (78\%), Cyathodinium sp. (68\%), Eimeria caviae (38\%), Paraspidodera uncinata (34\%) e Giardia muris (24\%). Nos exames de fezes realizados pelas técnicas de Ritchie e Kinyoun, foram encontrados os seguintes parasitos com as respectivas prevalências no biotério A: $\boldsymbol{E}$. caviae (74\%), Balantidium sp. (68\%), Cyathodinium sp. (68\%) e Cryptosporidium sp. (5\%). No biotério B, observou-se: $\boldsymbol{E}$. caviae (58\%), Balantidium sp. (42\%), Cyathodinium sp. (25\%) e G. muris (8\%). A alta prevalência de endoparasitos nos biotérios sugere a necessidade de se rever a eficácia das barreiras sanitárias adotadas.

Palavras-chave: cobaias, controle sanitário, protozoários, endoparasitos, helmintos.

\section{ABSTRACT}

This paper discusses the prevalence and intensity of infection of endoparasites in conventionally maintained Short Hair guinea pigs colonies from a breeding (A) and an experimental (B) facilities in Rio de Janeiro, Brazil. It also evaluates the efficacy of the methods of prevention adopted by both facilities. The search of parasites was performed by direct

\begin{abstract}
examination of intestinal mucosa and its contents, Wheatley's trichrome method and coproparasitological examinations by Ritchie's and Kinyoun's techniques. The prevalences of endoparasites found throught direct examination of intestinal mucosa and its contents were: Balantidium sp. (78\%), Cyathodinium sp. (68\%), Eimeria caviae (38\%), Paraspidodera uncinata (34\%) and Giardia muris (24\%). The prevalences of endoparasites found throught Ritchie's and Kinyoun's techniques in facility A were: E. caviae (74\%), Balantidium sp. (68\%), Cyathodinium sp. (68\%) and Cryptosporidium sp. (5\%). In facility B: E. caviae (58\%), Balantidium sp. (42\%), Cyathodinium sp. (25\%) and G. muris (8\%) were found. The high prevalences in both facilities suggest that the efficacy of the sanitary barriers adopted in the prevention of parasitic infections should be revised.
\end{abstract}

Key words: guinea pigs, health monitoring, endoparasites, protozoan, helminths.

\section{INTRODUÇÃO}

A cobaia é um animal amplamente utilizado como modelo experimental em pesquisas sobre anafilaxia, hipersensibilidade retardada, genética, cetoacidose, neuropatias ópticas, amebíase, escorbuto, leucemia, encefalomielite alérgica, colite ulcerativa, doenças infecciosas, imunologia e nutrição (HARKNESS \& WAGNER, 1993). No Canadá, foram utilizadas em experimentos cerca de 28.659 cobaias só no ano de 2002, correspondendo a $1,4 \%$ do total de animais utilizados em pesquisas nesse país

${ }^{\mathrm{I} C e n t r o ~ d e ~ C r i a c ̧ a ̃ o ~ d e ~ A n i m a i s ~ d e ~ L a b o r a t o ́ r i o ~(C E C A L), ~ F i o c r u z, ~ M a n g u i n h o s, ~ R i o ~ d e ~ J a n e i r o, ~ B r a s i l . ~}$

IIInstituto de Pesquisa Clínica Evandro Chagas (IPEC), Departamento de Micro-Imuno e Parasitologia, Serviço de Parasitologia, Fiocruz, Manguinhos, RJ,Brasil.

IIIPEC, Departamento de Doenças Infecciosas, Serviço de Zoonoses, Fiocruz, 21045-900, Manguinhos, RJ, Brasil. E-mail: rodcm@ipec.fiocruz.br.autor para correspondência. 
(CANADIAN COUNCIL ON ANIMAL CARE, 2005). No Brasil, o Centro de Criação de Animais de Laboratório (CECAL), pertencente à Fundação Instituto Oswaldo Cruz (FIOCRUZ), um dos maiores do país, forneceu para pesquisas 3.665 cobaias só no ano de 2004, o que torna o controle sanitário dos biotérios onde são criadas importante na obtenção de animais saudáveis e de qualidade para o uso em bioensaios. Dentre os agentes a serem monitorados estão os parasitos, cuja ocorrência pode ser usada como parâmetro confiável para avaliação das condições sanitárias nas quais os animais são mantidos, sendo indicadores da qualidade microbiológica desses e da presença de falhas nas barreiras sanitárias (PINTO et al., 2002). Além disso, já foi constatado que os parasitos de cobaia podem causar interferências nos resultados dos experimentos que utilizam esse modelo animal (CONDER et al., 1989).

Apesar da importância, são escassos os trabalhos sobre a prevalência e intensidade de infecção da fauna parasitária em cobaias provenientes de biotérios. No Brasil, houve um estudo recente sobre helmintos parasitos de cobaias realizado por PINTO et al. (2002), mas ainda há carência de informações sobre a presença de protozoários.

Os objetivos do presente trabalho foram: realizar um levantamento da prevalência e da intensidade de infecção de endoparasitos em cobaias oriundas de biotério de criação através do exame direto de mucosa e conteúdo intestinal e realizar exames coproparasitológicos em animais provenientes de biotérios de criação e experimentação do município do Rio de Janeiro, Brasil, avaliando-se a ocorrência dos parasitos e a eficácia das medidas de prevenção.

\section{MATERIAL E MÉTODOS}

Para pesquisa de endoparasitos através de exame direto de mucosa e conteúdo intestinal e coloração pela técnica de tricromo de Wheatley, foram examinadas sessenta e duas cobaias de linhagem Short Hair, convencionais, provenientes de um biotério de criação (A) do município do Rio de Janeiro, Rio de Janeiro, Brasil. As cobaias eram mantidas em grupos de seis a dez animais, em caixas de polipropileno medindo 90x60x30cm, com cama de maravalha de pínus autoclavada, onde recebiam ração peletizada da Guabi ${ }^{\circledR}$ e água filtrada com suplementação de vitamina $\mathrm{C}$ ad libitum. Os animais foram divididos em dois grupos: grupo de animais jovens, formado por vinte e sete cobaias, sendo doze fêmeas e quinze machos com idades variando entre quarenta e cinco e sessenta dias, e grupo de animais adultos, que continha trinta e cinco cobaias, sendo dezoito fêmeas e dezessete machos, com idades variando entre noventa e quinhentos e quarenta dias.

As cobaias foram submetidas à eutanásia com dose excessiva de tiopental via intraperitoneal, tendo sido realizado, em seguida, o exame direto de mucosa e conteúdo intestinal, no qual foi feita análise qualitativa e quantitativa dos endoparasitos de acordo com o seu habitat. O intestino foi dividido em três segmentos: intestino delgado, ceco, cólon juntamente com o reto. O ceco foi aberto e o intestino delgado, o cólon e o reto foram picados com auxílio de tesoura, em placas de Petri separadas, contendo solução de cloreto de sódio a $0,85 \%$. Essas placas foram examinadas em microscópio estereoscópio e, posteriormente, uma alíquota do líquido de cada uma delas foi coletada com pipeta para exame direto no microscópio óptico. Nas amostras positivas para protozoários, foi realizado um esfregaço em lâmina de microscopia, corado pelo tricromo de Wheatley (WHEATLEY, 1951), utilizandose o fixador de Schauddin modificado a base de sulfato de cobre (HOREN, 1981). Para morfometria, utilizou-se microscópio óptico equipado com micrômetro ocular e a identificação foi feita segundo FLYNN (1973) e VETTERLING (1976). Os nematóides encontrados foram coletados, fixados em AFA (álcool a 70 GL, 93\%; formaldeído, 5\%; ácido acético glacial, 2\%) à quente, corados pelo carmim alcoólico clorídrico de Langeron e preservados em bálsamo do Canadá segundo Amato (1985). A classificação dos nematóides foi feita de acordo com VICENTE et al. (1997). A carga parasitária dos helmintos foi quantificada de acordo com o número de espécimes encontrados: 1 a $50(+), 50$ a $100(++)$, e mais do que $100(+++)$. Por sua vez, a carga parasitária dos protozoários foi avaliada pelo número de cistos, oocistos ou trofozoítos encontrados por lâmina: 1 a $100(+), 101$ a $300(++)$ e mais do que $301(+++)$.

Para pesquisa de endoparasitos através das técnicas coproparasitológicas, foram coletadas individualmente dezoito amostras de fezes de cobaias fêmeas jovens, com idades entre vinte e três e trinta dias, do biotério A, e doze amostras individuais de fezes de um biotério de experimentação (B), de cobaias fêmeas, com aproximadamente trinta dias de idade, ambos localizados no município do Rio de Janeiro, Brasil. Os animais do biotério B eram mantidos em grupos de dois a três animais em caixas de polipropileno medindo $41 \times 34 \times 17,5 \mathrm{~cm}$, com cama de maravalha de pínus autoclavada, onde recebiam ração peletizada da Nuvital ${ }^{\circledR}$ e água filtrada com suplementação de vitamina $\mathrm{C}$ ad libitum. Os animais foram alojados individualmente e de cada caixa foi colhida uma quantidade mínima de $5 \mathrm{~g}$ de fezes frescas. As fezes coletadas em ambos os biotérios foram 
acondicionadas em frascos de coleta estéreis, devidamente identificados com o número do animal, sexo, idade, local e data da coleta e examinadas dentro de um prazo máximo de 24 horas.

As amostras fecais foram processadas pelo método de Ritchie (RITCHIE, 1948). As lâminas obtidas foram examinadas diretamente em microscópio óptico, sendo realizada a análise qualitativa e quantitativa dos helmintos e protozoários da mesma forma que na pesquisa de endoparasitos através de exame direto de mucosa e conteúdo intestinal. Com o sedimento obtido de cada amostra, foram confeccionados esfregaços finos e secados ao ar. Esses foram corados pela técnica modificada de Kinyoun a frio, de acordo com DE CARLI (1999), e examinados no microscópio óptico, em objetiva de imersão (1000x), para a pesquisa e morfometria de oocistos de Cryptosporidium sp. A identificação desse protozoário foi feita de acordo com XIAO et al. (2004).

Ambos os biotérios foram avaliados quanto às suas condições sanitárias segundo BAZZANO et al. (2002), relacionando a ocorrência de endoparasitos com a rigorosidade das barreiras sanitárias presentes.

\section{RESULTADOS}

Na análise do biotério A, através da técnica de exame direto da mucosa e do conteúdo intestinal e da coloração pela técnica de tricromo de Wheatley, foram encontrados os seguintes endoparasitos com as respectivas prevalências e cargas parasitárias: Balantidium sp., 78\% (+ a +++); Cyathodinium sp., 68\% (+ a +++$)$; Eimeria caviae, 38\% (+ a +++$)$; Paraspidodera uncinata, 34\% (+); Giardia muris, 24\% $(+\mathrm{a}+++)$. Os endoparasitos Balantidium sp. (Figura 1 A), P. uncinata (Figuras 1B, C, D), Cyathodinium sp. (Figura 1E) e $\boldsymbol{E}$. caviae (Figura $1 \mathrm{~F}$ ) foram encontrados no ceco, cólon e reto, enquanto $\boldsymbol{G}$. muris (Figura $1 \mathrm{G}$ ) foi observada no intestino delgado. Pelas técnicas de Ritchie e de Kinyoun, os endoparasitos diagnosticados foram: E. caviae, Balantidium sp., Cyathodinium sp., G. muris e Cryptosporidium sp. (Figura $1 \mathrm{H}$ ). Os valores de prevalência e carga parasitária dos parasitos diagnosticados nos biotérios A e B encontram-se na tabela 1. As medidas dos endoparasitos encontrados nos biotérios A e B foram: cistos de Balantidium sp., 38,4 a 62,8 x 31,2 a 51,6 $\mu \mathrm{m}$; cistos de Cyathodinium sp., 24,0 a 48,0 x 16,4 a 33,6 $\mu \mathrm{m}$; oocistos de $\boldsymbol{E}$. caviae, 14,4 a 28,8 x 12 a 21,6 $\mu$ m; cistos de $\boldsymbol{G}$ muris, 9,6 x 7,2 a 9,6 $\mu \mathrm{m}$; oocistos de Cryptosporidium sp. 5,9 x 3,9 a 4,9 $\mu \mathrm{m}$. A avaliação das condições sanitárias dos biotérios A e B encontra-se na tabela 2.

\section{DISCUSSÃO}

A prevalência de endoparasitos através de exame direto da mucosa e do conteúdo intestinal foi elevada, sendo o protozoário G. muris o menos prevalente, enquanto Balantidium sp. foi o mais prevalente. A presença desses dois parasitos é indesejável em cobaias destinadas a pesquisas, isso porque G. muris causa enterite acompanhada de alterações enzimáticas, histológicas, ultra-estruturais no intestino delgado e o Balantidium sp. é um patógeno secundário, causando enterite quando a flora intestinal encontra-se alterada por enteropatia bacteriana (VETTERLING, 1976; HANKINSON et al., 1982; NATIONAL INSTITUTES OF HEALTH, 1994).

O protozoário ciliado Cyathodinium sp. apresentou uma alta prevalência. Cunha (1914) foi quem primeiro descreveu Cyathodinium sp. no Brasil, tendo relatado três espécies: $\boldsymbol{C}$. conicum, $\boldsymbol{C}$. vesiculosum, identificadas a partir do preá (Cavia aperea), e $\boldsymbol{C}$. piriforme, a partir do preá e de cobaias (C. porcellus). Entretanto, sua patogenicidade, seu potencial zoonótico e as suas possíveis interferências em pesquisas ainda são desconhecidos.

Com relação ao nematóide $\boldsymbol{P}$. uncinata, a prevalência encontrada, igual a $40 \%$, foi semelhante à constatada em investigação realizada no Brasil por PINTO et al. (2002) em cobaias provenientes de pet shops, sendo porém superior à prevalência de $10 \%$ observada pelos mesmos autores em um biotério convencional. CONDER et al. (1989), em cobaias clinicamente normais, relataram aumento de eosinófilos nos pulmões associado à presença de $\boldsymbol{P}$. uncinata, interferindo nos seus estudos sobre populações celulares no lavado broncoalveolar, o que mostra que esse endoparasito é indesejável nos animais destinados à experimentação. Todavia, não possui potencial zoonótico(VETTERLING, 1976).

O protozoário $\boldsymbol{E}$. caviae foi também encontrado freqüentemente nesse estudo, o que é preocupante. Isso porque, apesar de ser espécieespecífico e não possuir potencial zoonótico, pode causar colite hemorrágica, levando a diarréia e morte de cobaias (VETERLLING, 1976; HURLEY, 1995).

A prevalência e a carga parasitária dos endoparasitos através das técnicas de Ritchie e de Kinyoun em ambos os biotérios foram altas, sendo o protozoário E. caviae o mais prevalente. A fauna parasitária do biotério $\mathrm{B}$ diferiu do biotério A pela presença de $\boldsymbol{G}$. muris, que foi o endoparasito menos prevalente, enquanto somente no biotério A foi encontrado Cryptosporidium sp.

Ciência Rural, v.37, n.5, set-out, 2007. 


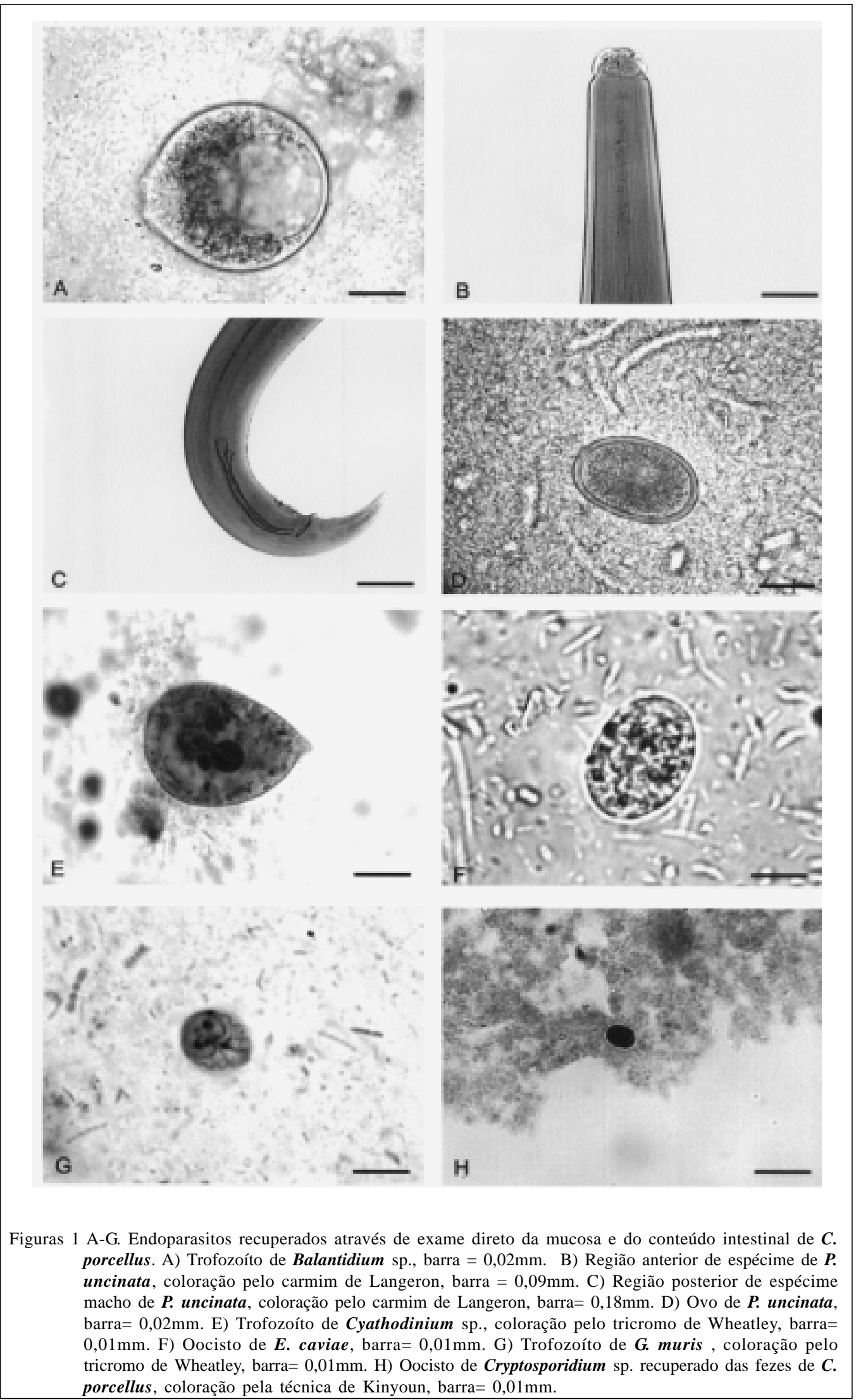

Ciência Rural, v.37, n.5, set-out, 2007. 
Tabela 1 - Prevalência e carga parasitária dos endoparasitos encontrados em cobaias dos biotérios A e B através das técnicas de Ritchie e Kinyoun.

\begin{tabular}{lcc}
\hline & & Prevalência (carga parasitária) \\
\hline Endoparasitos & Biotério A $(\mathrm{n}=18)$ & Biotério B $(\mathrm{n}=12)$ \\
E. caviae & $74 \%(+\mathrm{a}+++)$ & $58 \%(+\mathrm{a}++)$ \\
Balantidium sp. & $68 \%(+\mathrm{a}++)$ & $42 \%(+)$ \\
Cyathodinium sp. & $68 \%(+\mathrm{a}+++)$ & $25 \%(+)$ \\
G. muris & & $08 \%(+)$ \\
Cryptosporidium sp. & $05 \%(+)$ & - \\
\hline
\end{tabular}

A prevalência de Cryptosporidium sp. em cobaias encontradas neste trabalho foi baixa e semelhante à relatada por SEOK et al. (2005), que encontraram esse parasito em $4 \%$ dos camundongos e em $6 \%$ dos ratos convencionais em cinco biotérios de criação na Coréia do Sul, através da histopatologia do estômago. GIBSON \& WAGNER (1986) reportaram em 2.348 cobaias examinadas uma prevalência de 3,4\% através da histopatologia intestinal. Apesar da baixa prevalência, deve ser considerado o potencial zoonótico de Cryptosporidium sp. e o fato de causar doença, morte e alterações no sistema imune desses animais, como mastocitose na mucosa gástrica, além de dificultar a interpretação de lesões intestinais e distorcer resultados experimentais (HARKNESS \& WAGNER, 1993; RHEE et al., 1997).
A ausência de ovos de $\boldsymbol{P}$. uncinata nas fezes examinadas pela técnica de Ritchie pode ser explicada pela sua baixa carga parasitária encontrada na presente pesquisa ou pelo seu longo período pré-patente de sessenta e seis dias constatado por HERLICH \& DIXON (1965), já que os animais utilizados neste estudo possuíam em torno de 30 dias de vida.

As medidas dos cistos de Balantidium estão de acordo com FLYNN (1973) e VETTERLING (1976) para B. coli e B. caviae. Porém, devido à semelhança morfométrica entre elas, não foi possível classificar a espécie encontrada. Por isso, não se deve descartar a hipótese de as cobaias estarem infectadas pela espécie $\boldsymbol{B}$. coli, que possui potencial zoonótico, podendo causar diarréia e disenteria no homem.

Tabela 2 - Avaliação dos biotérios de criação (A) e experimentação (B) de cobaias.

\begin{tabular}{|c|c|c|}
\hline \multicolumn{3}{|c|}{ Biotérios } \\
\hline Parâmetros avaliados & A & $\mathrm{B}$ \\
\hline Controle ambiental & Não & Não \\
\hline Temperatura & 22 a $23^{\circ} \mathrm{C}$ & 20 a $22^{\circ} \mathrm{C}$ \\
\hline Umidade relativa & 55 a $60 \%$ & 65 a $70 \%$ \\
\hline Controle sanitário periódico & Sim & Não \\
\hline \multicolumn{3}{|l|}{ Higiene e biossegurança } \\
\hline Material esterilizado & Não & Não \\
\hline Ração autoclavada & Não & Não \\
\hline Água filtrada & Sim & Sim \\
\hline Desinfecção & Sim (caixas) & Sim (caixas) \\
\hline Limpeza das caixas & 2 vezes por semana & 3 vezes por semana \\
\hline Limpeza geral & Quinzenal & Quinzenal \\
\hline Uniforme apropriado & Sim & Sim \\
\hline Restrições (exemplo: uso de cosmético) & Sim & Sim \\
\hline Banho & Não & Não \\
\hline Troca completa de uniforme & Diariamente & Diariamente \\
\hline Uso de botas & Sim & Sim \\
\hline \multicolumn{3}{|l|}{ Quadro de funcionários } \\
\hline Profissionais em bioterismo & Sim & Sim \\
\hline Estagiários & Não & Não \\
\hline
\end{tabular}


Os valores mínimo e máximo de morfometria encontrados para os oocistos de $\boldsymbol{E}$. caviae são semelhantes aos descritos por HENRY (1932) e HURLEY et al. (1995).

As medidas dos cistos de Cyathodinium encontradas no presente trabalho foram maiores do que aquelas descritas na literatura para $\boldsymbol{C}$. piriforme, e a espécie $\boldsymbol{C}$. cunhai ainda não teve seus cistos descritos (FLYNN, 1973; VETTERLING, 1976).

A espécie de Giardia encontrada foi identificada como $\mathbf{G}$. muris, que parasita somente roedores, aves e répteis, segundo a classificação de MEYER (1985), e os dados morfométricos dos seus cistos foram descritos pela primeira vez em cobaias no presente estudo.

Apesar de os oocistos de Cryptosporidium sp. encontrados possuírem medidas semelhantes às da espécie $\boldsymbol{C}$. wrairi , específica de cobaias, relatadas por XIAO et al. (2004), é necessária a caracterização molecular para confirmá-la.

As barreiras sanitárias adotadas pelas duas instituições analisadas mostraram-se ineficazes no controle de endoparasitos. Considerando-os como indicadores da qualidade microbiológica, outros agentes como bactérias e vírus patogênicos podem estar presentes e se disseminando, comprometendo ainda mais a utilização desses animais em pesquisas. BAZZANO et al. (2002) mostraram que é possível a obtenção de animais convencionais livres de parasitos através de medidas rigorosas, além das já adotadas pelos biotérios avaliados neste trabalho. Dentre elas, a limpeza geral das instalações a cada semana, a limpeza das salas dos animais três vezes por semana, banho, troca de uniforme e do protetor de sapatos dos tratadores duas vezes ao dia. Também, de acordo com NICKLAS et al. (2002), é necessário um monitoramento sanitário periódico e atuante, que não esteja limitado a relatar os resultados laboratoriais, mas também que envolva a comunicação entre os técnicos dos animais, diretores dos biotérios, veterinários e pesquisadores de modo que as anormalidades observadas possam ser avaliadas e ações apropriadas tomadas. De acordo com o NATIONAL RESEARCH COUNCIL (1996), o tratamento com drogas antiparasitárias, mesmo altamente eficazes, dificilmente erradica o parasitismo de uma grande colônia de animais altamente infectada, como as investigadas no presente estudo, além de causar efeitos colaterais nos animais e interferir nos resultados de experimentos. O que é recomendado nesses casos é a eutanásia e o repovoamento da colônia com animais livres de doenças, após desinfecção das instalações e dos equipamentos.

\section{CONCLUSÕES}

Os valores de prevalência e carga parasitária dos endoparasitos encontrados nos biotérios A e B foram elevados, demonstrando que houve falhas nas barreiras sanitárias desses biotérios.

Os protozoários Cryptosporidium sp., Balantidium sp., E. caviae e $\boldsymbol{G}$. muris foram pela primeira vez relatados em cobaias de laboratório no Brasil, juntamente com os seus dados morfométricos, comprovando a carência de estudos com relação aos endoparasitos dessa espécie animal no país e fornecendo elementos para um diagnóstico mais preciso desses agentes pelos profissionais responsáveis pelo controle da qualidade em biotérios.

\section{AGRADECIMENTOS}

Agradecemos à professora Simone Sant'Anna pela versão do resumo para o inglês; a Margarida de Jesus Barbosa, Josilene Pedreira Soares de Andréa e aos técnicos Alex da Silva Almeida, Cátia Lúcia Martins Lopes, Néviton Rodrigues das Neves e Carlos Henrique, por sua colaboração neste trabalho.

\section{COMITÊ DE ÉTICA}

O desenvolvimento deste trabalho foi autorizado pelo Comitê de Ética para o Uso de Animais (CEUA/FIOCRUZ) através do programa $n^{\circ}$ P0044-00.

\section{REFERÊNCIAS}

AMATO, J.F. Manual de técnicas para a preparação de coleções zoológicas. 8. Platelmintos (temnocefálidos, trematódeos, cestóides, cestodários) e acantocéfalos. São Paulo: Sociedade Brasileira de Zoologia, 1985. 11p.

BAZZANO, T. et al. Patterns of infection with the nematodes Syphacia obvelata and Aspiculuris tetraptera in Conventionally Maintained Laboratory Mice. Memórias do Instituto Oswaldo Cruz, Rio de Janeiro, v.97, n.6, p.847-853, 2002.

CANADIAN COUNCIL ON ANIMAL CARE. Canadian Council on Animal Care annual report 2004-2005. Capturado em 26 jul. 2006. Online. Disponível na Internet: http://www.ccac.ca/en/Publications/PUBLICAT/Annualre/ ccac_ar_2004-2005_en.pdf.

CONDER, G.A. et al. Bronchoalveolar eosinophilia in guinea pigs harboring inapparent infections of Paraspidodera uncinata. Journal of Parasitology, Lawrence, v.75, n.1, p.144-146, 1989.

CUNHA, A.M. Sobre os ciliados intestinais dos mamíferos. Memórias do Instituto Oswaldo Cruz, Rio de Janeiro, v.6, p.212-216, 1914.

DE CARLI, G.A. Diagnóstico laboratorial da Cyclospora cayetanensis. Revista Brasileira de Análises Clínicas, Rio de Janeiro, v.31, p.143-150, 1999. 
FLYNN, R.J. Parasites of laboratory animals. 5.ed. Ames: The Iowa State University, 1973. 884p.

GIBSON, S.V.; WAGNER, J.E. Criptosporidiosis in guinea pigs: a retrospective study. Journal of the American Veterinary Medical Association, Schaumburg, v.189. n.9, p.1033-1034, 1986.

HANKINSON, G.J et al. Diagnostic exercise. Laboratory Animal Science, Memphis, v.32, n.1, p.35-36, 1982.

HARKNESS, J.E.; WAGNER, J.E. Biologia e clínica de roedores. 3.ed. São Paulo: Roca, 1993. 238p.

HENRY, D.P. Coccidiosis of the guinea pig. University of California Publications in Zoology, Bekerly, v.37, p.211268, 1932.

HERLICH, H.; DIXON, C.F. Growth and development of Paraspidodera uncinata. Journal of Parasitology, Lawrence, v.51, n.2, p.300, 1965.

HOREN, W.P. Modification of Schaudinn fixative. Journal of Clinical Microbiology, Washington, v.13, p.204-205, 1981.

HURLEY, R.J. et al. Diagnostic exercise: depression and anorexia in recently shipped guinea pigs. Laboratory Animal Science, Memphis, v.45, n.3, p.305-308, 1995.

MEYER, E.A. The epidemiology of giardiasis. Parasitology Today, Amsterdam, v.1, n.4, p.101-105, 1985.

NATIONAL INSTITUTES OF HEALTH. Manual of microbiologic monitoring of laboratory animals. 2.ed. United States: NIH, 1994. 225p.

NATIONAL RESEARCH COUNCIL. Laboratory animal management: rodents. Washington: National Academy, 1996. 167p.
NICKLAS, W. et al. Recommendations for the health monitoring of rodent and rabbit colonies in breeding and experimental units. Laboratory Animals, London, v.36, p.2042, 2002.

PINTO, R.M. et al. Helminths of the guinea pig, Cavia porcellus (Linnaeus), in Brazil. Revista Brasileira de Zoologia, Curitiba, v.19, n.1, p.261-269, 2002.

RHEE, J.K. et al. Effects of Cryptosporidium muris (Strain MCR) infection on gastric mucosal mast cells in mice. The Korean Journal of Parasitology, Seoul, v.35, n.4, p.245249, 1997.

RITCHIE, L.S. An ether sedimentation technique for routine stool examinations. Bulletin of the United States Army Medical Department, Washington, v.8, p.326, 1948.

SEOK, S. et al. Health surveillance of specific pathogen-free and conventionally-housed mice and rats in Korea. Experimental Animals, Tokyo, v.54, p.85-92, 2005.

VETTERLING, J.M. Protozoan parasites. In: WAGNER, J.E.; MANNING, P.J. (Eds.). The biology of the guinea pig. New York: Academic, 1976. p.163-196.

VICENTE, J.J. et al. Nematóides do Brasil. Parte V: nematóides de mamíferos. Revista Brasileira de Zoologia, Curitiba, v.14, n.1, p.1-452, 1997.

XIAO L. et al. Cryptosporidium taxonomy: recent advances and implications for public health. Clinical Microbiology Reviews, Washington, v.17, n.1, p.72-97, 2004.

WHEATLEY, W.B. A rapid staining procedure for intestinal amebae and flagellates. American Journal of Clinical Pathology, Philadelphia, v.21, p.990-991, 1951. 